\title{
Design and Realization of a VRGIS-Based Digital Agricultural Region Management System
}

\author{
Xiaojun Liu, Yuou Zhang, Weixing Cao, and Yan Zhu ${ }^{* *}$ \\ Jiangsu Key Laboratory for Information Agriculture, \\ Nanjing Agricultural University, Nanjing 210095, China \\ Tel.: 025-84396565, Fax: 025-84396672 \\ liuxj@njau.edu.cn, yanzhu@njau.edu.cn
}

\begin{abstract}
In order to realize the digitalization and visualization of information management in agricultural-region, a VRGIS-based digital agricultural region management system (VDARMS) was developed with SuperMap 2008 as the platform of spatial information management, VRMap 3.0 as the driver of scene, and integrating with the existing knowledge model for crop management. This system realized the functions as file management, spatial handling, information query, data analysis, cultural management plan design, virtual simulation, and system maintenance, etc. Case studies of the system were carried out in Heheng village of Jiangyan city and Qinglong village of Nanjing city, Jiangsu province, China, the application results indicated that VDARMS accorded with the development of modern agricultural spatial information management, realized standard, digital management and visual display of agricultural information, and greatly promoted the development of digital agriculture technology.
\end{abstract}

Keywords: VRGIS, agro-region, knowledge model for crop management, information management, virtual simulation.

\section{Introduction}

Along with the development of information and computer technologies, digital agriculture has been an effective method for many countries to promote the skills of agricultural production and improve the capacity of agricultural competition (Liu, 2005; Song et al., 2007; Zhou, 2009). Agricultural information management system is one of the core technologies in the technological system of digital agriculture. Up to now, correlative researches were reported at home and abroad, for example, Shane et al. (2001) in Kansas State University developed a field-level geographic information system based on object-oriented programming concept. Ma et al. (2007) established a spatial information management system of digital agriculture by using ComGIS

\footnotetext{
Project supported by the National High-Technology Research and Development Program of China (No. 2006AA10A303).

** Corresponding author.
} 
technology. Liu et al. (2006) designed and realized a WebGIS-based system for agricultural spatial information management and aided decision-making with Brower/Server mode as distributing network structure and WebGIS as spatial information management platform. These systems were mostly developed based on GIS, had the functions as information query, spatial analysis and aided decision- making. However, geometrical and topological information in the third dimension (vertical direction) were disappeared for using $2 \mathrm{D}$ showing mode in expressing spatial information, so the realistic world cannot be exhibited perfectly.

Virtual reality geographic information system (VRGIS) is one of the pop research domains in geographic information system (GIS) and virtual reality (VR). As the integrating combination of GIS and VR, VRGIS has the functions as spatial information management of GIS and virtual visualization of VR, user can observe, immerge and communicate in the virtual environment (Deng et al., 2002). Recently, several correlative researches based on VRGIS were reported in the domains of urban layout, forest resource management and tour resources management, moreover, a series of virtual simulation systems were developed (Jiang et al., 2008; Zou et al., 2006; Liu et al, 2006; Wu et al, 2008). Although these systems realized the functions as 3D wandering, data management and information query, but couldn't realize the spatial information analysis and decision support. Therefore, the object of this paper is to develop a VRGIS-based digital agricultual region management system by integrating the technologies of VRGIS, crop management knowledge model, database and decision support system $(\mathrm{Cao}, 2008)$. The system aims to realize the functions such as digitalization management for agro-region information, aided decision-making for crop cultivation and visualization simulation display, furthermore improve the efficiency and effect of information management and display in agro-region.

\section{Design of System}

\subsection{Design of System Structure}

Based on the theory of system engineering, software technology, research target and technology characteristic, the system was composed of three parts: user layer, operational logic layer and basal data layer (Fig. 1).

\subsubsection{Basal Data Layer}

The Basal Data Layer Managed Elementary Data and 3D Model Data.

Elementary data: included spatial and attributive data. The spatial data included the data as road, watershed, building and field in agro-region. The attributive data was composed of elementary attributive data and geographic attributive data. The first one consisted of agricultural resource data that driving model run and scene constructing parameters, such as meteorological data, soil data, variety parameter data and terrain creating parameters, etc; the second one was the data that described spatial characters, such as position, area, aspiration information of building, crop type, yield and variaty information, etc, these data were connected with spatial data by correlative code. 


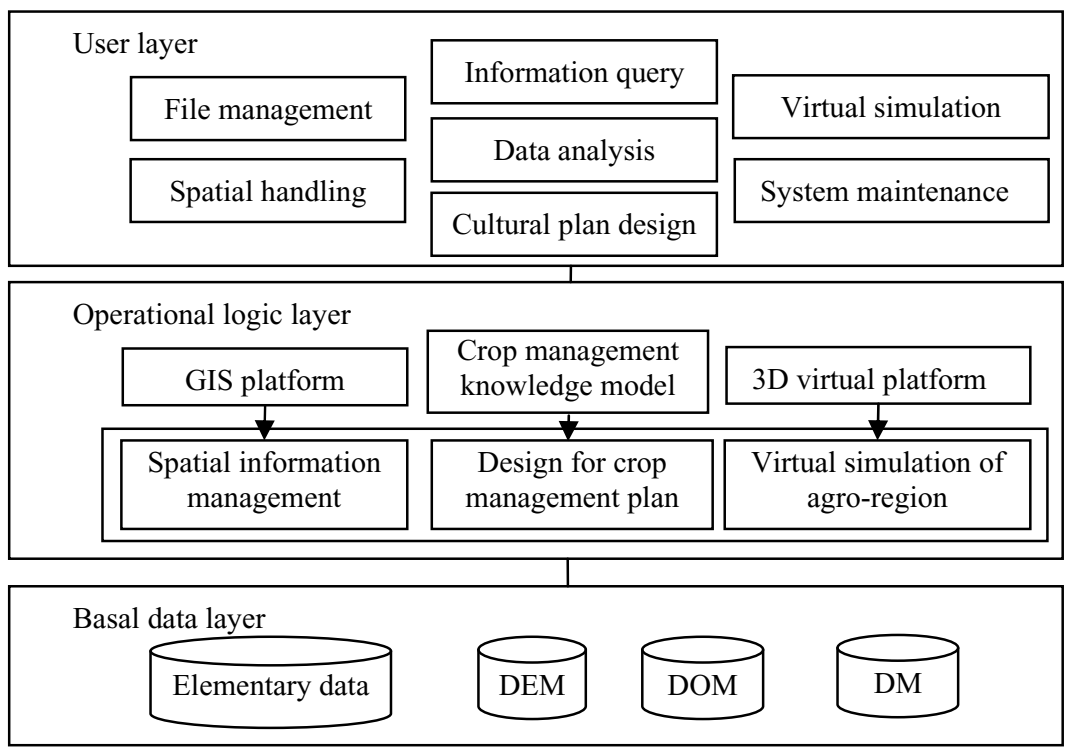

Fig. 1. Framework of system

3D model data: included digital elevation model (DEM), digital orthograph model (DOM) and digital model (DM). DEM was used to simulate the variable status of terrain by digital vector and grid formats (Huang et al., 2001). DOM was the digital image to express the 3D model's textures (Hu, 2007), DM was the 3D model of ground object with complicated structure by 3D modeling software (such as 3DS Max), moreover it was the foundation of 3D virtual scene.

\subsubsection{Operational Logic Layer}

The operational logic layer consisted of spatial information management module, plan design module for crop cultivation and virtual simulation module of agricultural-region, three modules were integrated based on data level and COM components. The first module could realize information query, data analysis, display of thematic map and maintenance by GIS platform. The second module could realize the decision support for agricultural production management based on existing crop management knowledge model, result data were transferred to GIS platform and 3D virtual platform to fulfill the display of thematic map and virtual scene. The third module could realize the display and alternation of 3D virtual scene, alternation between 2D digital map and $3 \mathrm{D}$ scene on the $3 \mathrm{D}$ virtual platform.

\subsubsection{User Layer}

Taking Windows as system interface, the system could communicate with user by menu, toolbar, list table, map and 3D virtual scene, etc. By clicking the mouse or keyboard, user could operate the functions such as file management, spatial handling, information query, data analysis, crop cultural plan design, virtual simulation and system maintenance, etc. 


\subsection{Design of System Function}

In order to realize the digitalization and visualization of information management in agricultural region, and supply the convenient alternation, the functions of file management, spatial handling, information query, data analysis, cultural plan design, virtual simulation and system maintenance were designed in this system (Fig. 2).

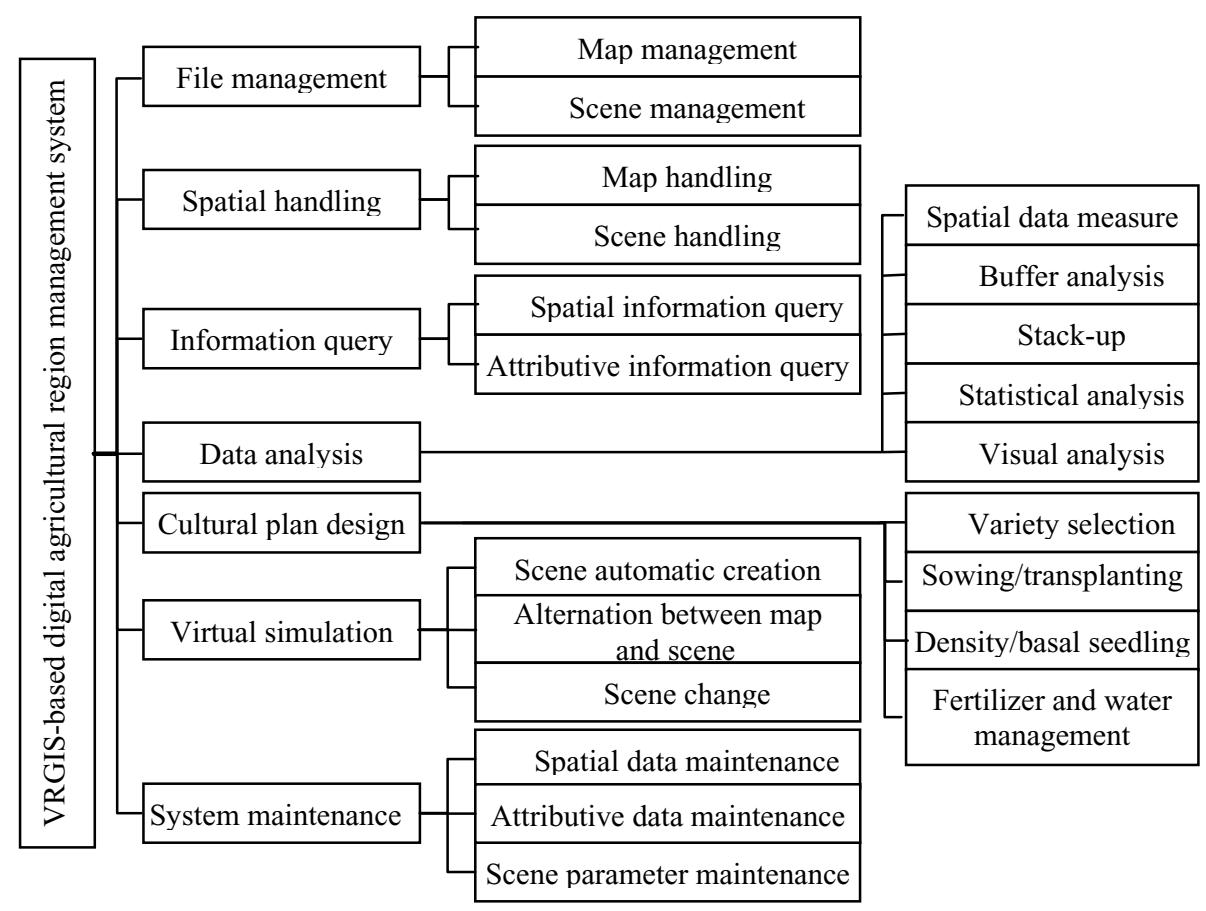

Fig. 2. Functional chart of system

\section{System Realization}

\subsection{Basal Data Disposal}

\subsubsection{Construction of Spatial Database}

The original spatial data of agricultural region were acquired from RS images and GPS coordinates by manual vectorization, disposed data were stored into spatial database by spatial data engine of GIS. SuperMap 2008 software can easily realize the operations as data browse, data edit, information query, result output, spatial analysis and 3D modeling for its good alternating interfaces and convenient handling. Furthermore, all kinds of spatial objects and RS image data can store into database or file by spatial data engine of SuperMap SDX+. Based on all these virtues, we selected SuperMap Deskpro 2008 software to design and develop the spatial database of system.

The attributive data of agricultural region were gathered by collecting historical data and field survey, in which the geographic attributive data were stored into the spatial 
database, and the elementary attributive data were stored into the attributive database via Microsoft Access 2007.

\subsubsection{DEM Disposal}

DEM were the models used to simulate change status of terrain wave by digital vector and grid formats. These data were disposed by grid simplified algorithm to control the level of detail (LOD) process, and form the different detail level of terrain data.

\subsubsection{DOM Disposal}

DOM was composed of disposed digital navigation photo and satellite RS image, these data could be used to optimize the texture of 3D models and control background status of terrain by geometrical rectification and inlay.

\subsubsection{DM Making}

DM were the 3D models with complicated structural characteristic, which were made by 3DS Max software, such as the models of building, road and field, etc. In order to make VDARMS have a better performance, models must be developed based on little triangle faces by polygon modeling function of 3DS Max software, additionally, vivid texture picture would be stuck onto the surface of models.

\subsection{Construction of 3D Virtual Scene}

The main work in the virtual simulation module of agricultural region was concentrated on setting up 3D virtual scene, so the constructing procedure and fidelity of 3D virtual scene would directly affect the quality of system. Recently, there are many good 3D virtual simulation platforms at home and abroad, by comparing the platforms and considering the actual condition of agricultural region, VRMap 3.0 was selected as the scene driver of VRGIS which supplied key technologies as management of mass data, display of advanced simulation, communication among different platforms and database driver. In the procedure of constructing scene, the program could automatically create $3 \mathrm{D}$ virtual scene by using correlative parameters inputted by user in the attributive database (Table.1), and showed high reusability and flexibility.

Table 1. Parameters of scene creation

\begin{tabular}{|c|c|c|}
\hline Parameter type & $\begin{array}{c}\text { Parameter name } \\
\end{array}$ & Plug name \\
\hline $\begin{array}{l}\text { Terrain creating } \\
\text { parameters }\end{array}$ & $\begin{array}{l}\text { Scene name, terrain texture name, } \\
\text { maximum and minimum longitude, } \\
\text { maximum and minimum latitude }\end{array}$ & Terrain creating plug \\
\hline $\begin{array}{l}\text { Object importing } \\
\text { parameters }\end{array}$ & $\begin{array}{l}\text { Coordinate, object name and rotation, } \\
\text { agro-region name, model name, conjunct } \\
\text { code, numbers of transverse and } \\
\text { longitudinal models, degrees of transverse } \\
\text { and longitudinal excursions }\end{array}$ & $\begin{array}{l}\text { Standard importing } \\
\text { and exporting plug }\end{array}$ \\
\hline $\begin{array}{l}\text { Background creating } \\
\text { parameters }\end{array}$ & $\begin{array}{l}\text { Sky radius, bottom color of sky, top color } \\
\text { of sky, texture picture name of sky, } \\
\text { texture picture name of ground }\end{array}$ & Standard creating plug \\
\hline $\begin{array}{l}\text { Light creating } \\
\text { parameters }\end{array}$ & Type, coordinate, angle & Standard creating plug \\
\hline $\begin{array}{l}\text { Camera adding } \\
\text { parameters }\end{array}$ & Type, name, coordinate, angle & Standard creating plug \\
\hline
\end{tabular}




\subsection{Alternation between Digital Map and Virtual Scene}

Each object from agricultural region was distributed a code to be distinguished each other and make for managing and querying spatial information. These were stored into spatial and attributive databases via conjunct code, and used to realize the alternation between digital map and virtual scene. This function was designed under the query menu of virtual simulation module. The acting procedure was: (1) stored the code into the scene as the name of correlative 3D model; (2) acquired the name of 3D model by VRMap 3.0 SDK engine; (3) queried the information of correlative spatial object by SuperMap SDX+ engine, realized the function of real-time alternation.

\subsection{Change of Crop Landscape}

The landscapes of crops show different forms at different growth stages and varieties. Considering the characters of crops in different growth stages, changing large-scale crop landscapes was realized by selecting the main growth stages to carry out the replacement for 3D models of fields. The acting procedure was: (1) first of all, added all the fields into the VRMapSelectionSet. (2) secondly, got the name, coordinate, rotation, zoom-adaption and remotion of one field object by IVRMapPMObjectDisp. (3) finally, replaced the 3D model of field with the obtained information by CreatePMObjectFrom3DS, and then transferred to another field until all the fields were changed.

\subsection{System Development}

The VRGIS-based digital agricultural region management system was developed on the computer with Intel(R) Core (TM) 2 Duo CPU, $1 \mathrm{G}$ memory and Windows XP Professional operating system(Version: Chinese). By applying Visual Basic 6.0 to design the interface of system, SuperMap Deskpro 2008 to design spatial database, Microsoft Access 2007 to disign attributive database. The 3D models were set up on the platform of 3DS Max 2009 software, the modules of spatial information management and crop management plan design were developed by using the components of SuperMap Objects 2008 and existing crop management knowledge model, while the 3D virtual scene and the module of virtual simulation of agricultural region were established by VRMap 3.0 software.

\section{System Application}

Case studies of the system were carried out in Heheng village of Jiangyan city and Qinglong village of Nanjing city, Jiangsu province, China. The executing procedure was: Firstly, the spatial and attributive databases were constructed with Google Earth images, digital photos and data resources via vectorization and tabulation. Secondly, the 3D models of building, road and field in the agro-region were made by 3D modeling software. Finally, all the data were imported into system. The application results indicated that the structure framework and design idea of VDARMS accorded with the 
development demand of modern agricultural information technology, realized the standard management and convenient query of information in agro-region, prescription design for crop management, and alternation between map and scene. At the same time, the function of virtual simulation also realized the automatic constructing and wandering of 3D virtual scene for rice and wheat in different growth stages (Fig.3-Fig.6).

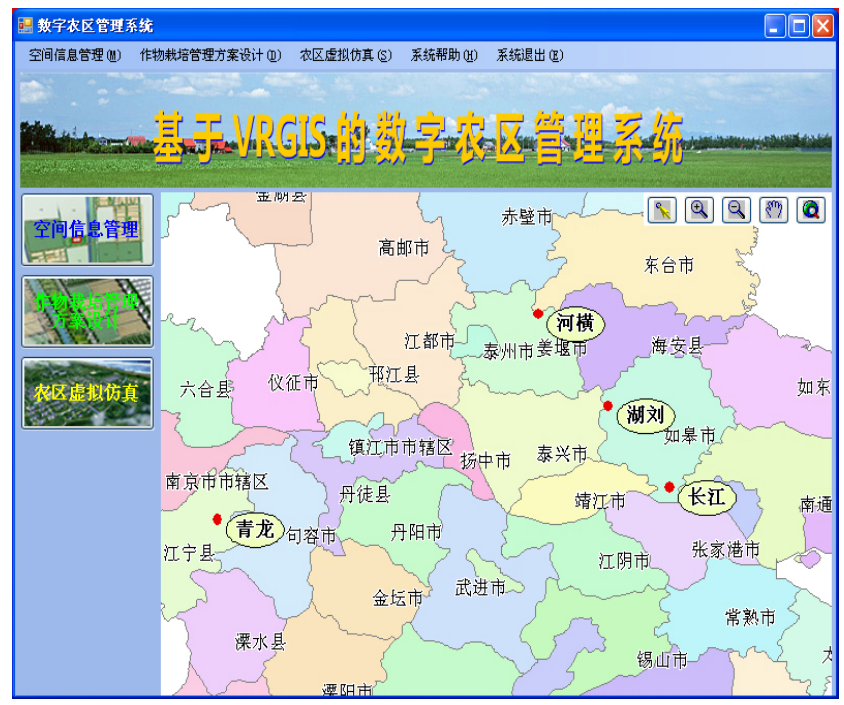

Fig. 3. Main interface of VDARMS

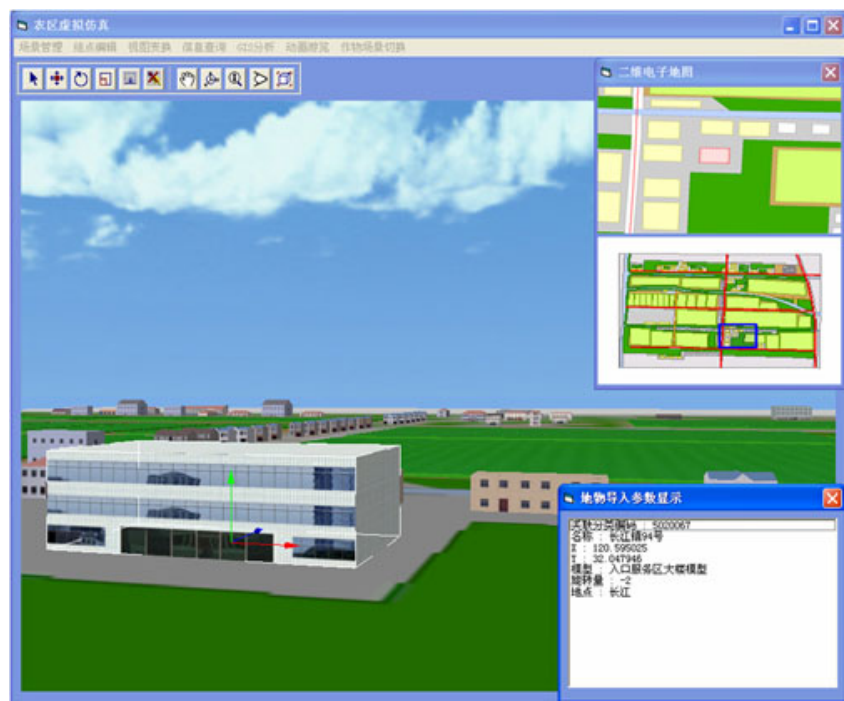

Fig. 4. Alternation between map and scene in Heheng village 


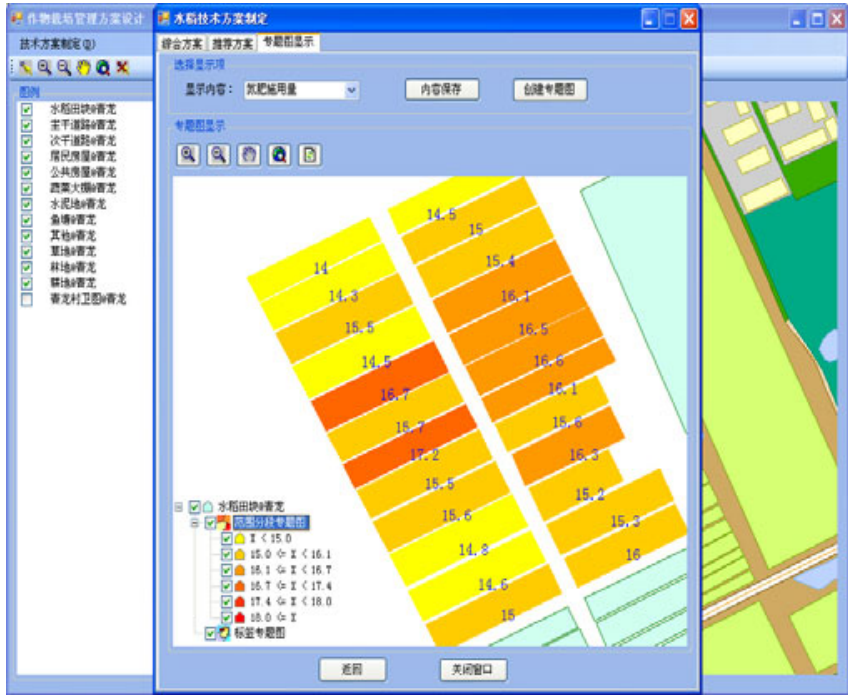

Fig. 5. Prescription map of total nitrogen of rice in Qinglong village

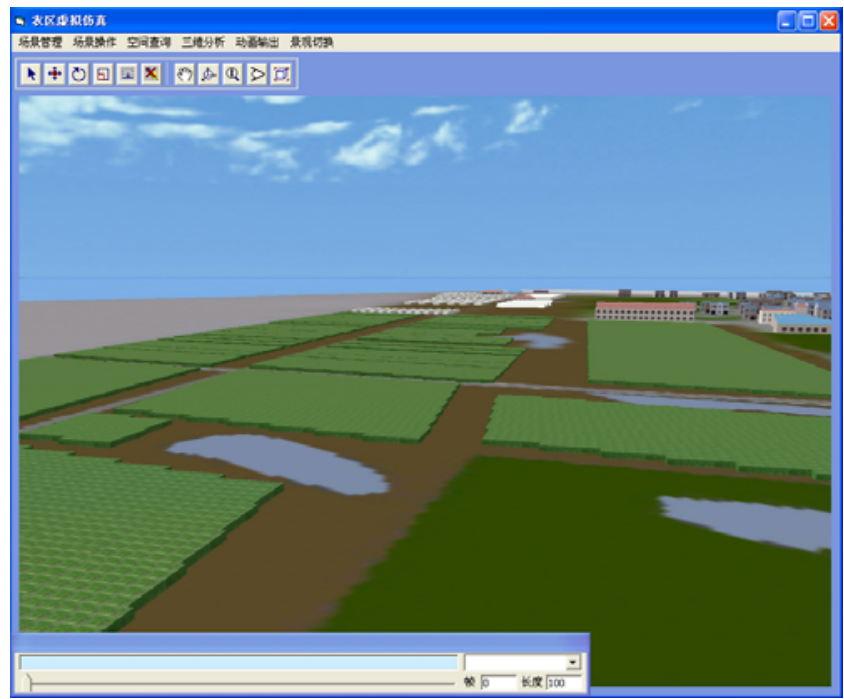

Fig. 6. Virtual scene of rice jointing stage in Qinglong village

\section{Discussion}

In order to realize the digitalization and visualization of information management in agricultural-region, a VRGIS-based digital agricultural region management system was developed with SuperMap 2008 as the platform of spatial information management and VRMap 3.0 as the driver of scene, and integrating with the existing crop model 
resources. The system had the functions as file management, spatial handling, information query, data analysis, prescription design for crop cultural management, virtual simulation and system maintenance, etc. Case studies of the system were carried out in Heheng village of Jiangyan city and Qinglong village of Nanjing city, Jiangsu province, the application result indicated that it accorded with the development of modern agricultural spatial information management, realized the standardization, digital management and visual display of agricultural information. The results provided a digital and visual platform for the construction and management of new countryside, exceedingly promoted the development of digital agriculture.

Comparing with the existing agricultural spatial information management systems and virtual simulation systems(Shane et al., 2001; Ma, 2007; Liu et al., 2006; Jiang et al., 2008; Zou et al., 2006; Liu et al., 2006; Wu et al., 2008), the system has the following characters: (1) the display of spatial information is not only in the nonfigurative 2D space, but also in the dynamic and communicated 3D space, user can apperceive the real world by a intuitionistic manner; (2) by setting the parameters for the construction of scene and using the function of plug, the system can automatically and quickly construct the 3D virtual scene of agro-region. The weakness of costing much time in establishing 3D virtual scene and fixed applied object was overcame, and exceedingly promoted the reusability of virtual simulation technology. (3) the alternation of digital map and virtual scene eliminated the wildering sense in wandering $3 \mathrm{D}$ virtual scene, effectively showed the integrity of 2D digital map and the visualization of $3 \mathrm{D}$ virtual scene, and perfectly annotated the spatial information of agro-region.

However, on account of the integration between GIS and VR based on data level, additional studies should be undertaken on the same data structure to realize the absolute integration; Further, considering the limitations of 3D GIS and computer technologies, the system should be updated by VRMap 4.0 or higher version of 3DGIS software to improve the efficiency of system running.

\section{References}

1. Liu, W.: The Origin and the Initial Practice of the Digital Agriculture. Agriculture Network Information 8, 21-23 (2005) (in Chinese)

2. Song, Z., Zhang, J.: Study Progress and Development Trend of Digital Agriculture. Modernization Agriculture 5, 1-4 (2007) (in Chinese)

3. Zhou, Y.: 3S Technique and Digital Agriculture. Bulletin of Surveying and Mapping 5, 69-71 (2009) (in Chinese)

4. Shane, R., Naiqian, Z., Taylor, R.K.: Development of a Field-Level Geographic Information System. Computer and Electronics in Agriculture 31, 201-209 (2001)

5. Ma, Q., Zhang, B., Zhang, C.: Developing and Studying of Spatial Information Management System of Digital Agriculture Based on COM GIS. Computer System Application 4, 86-89 (2007) (in Chinese)

6. Liu, X., Zhu, Y., Yao, X., et al.: WebGIS-Based System for Agricultural Spatial Information Management and Aided Decision-Making. Transactions of the CSAE 22(5), 125-129 (2006) (in Chinese)

7. Deng, H., Wu, F., Yin, C.: Virtual Reality Geographic Information System (VRGIS)-a New Field of the Research of GIS. Application Research of Computers 9, 33-35 (2002) (in Chinese) 
8. Jiang, J., Wen, X., She, G.: Research and Application of VRGIS in Forest Resources Management. Forest Research 21, 134-137 (2008) (in Chinese)

9. Zou, J., Zou, Z., Zhou, C., et al.: Study on Large-Scale City VR Simulation System and its Realization. Journal of System Simulation 18(8), 2199-2202 (2006) (in Chinese)

10. Liu, J., Yu, H., Han, Y., et al.: Development of Tourist Area Virtual Simulation System Based on VRMap. Journal of System Simulation 18(1), 130-133 (2006) (in Chinese)

11. Wu, H., Zhong, X., Zhao, C., et al.: Realization of the Dynamic Interactive 3D Virtual Wandering System in the Rural Community Based on VRML. Transactions of the CSAE 24(2), 176-180 (2008) (in Chinese)

12. Cao, W.: Digital Farming Technology. Science Press, Beijing (2008) (in Chinese)

13. Huang, X., Ma, J., Tang, Q.: An Introduction to Geographic Information System. Higher Education Press, Beijing (2001) (in Chinese)

14. Hu, Z.: Implementation of Shenzhen Private House 3D Demonstration System. Geomatics and Spatial Information Technology 30(3), 133-135 (2007) (in Chinese) 